\title{
Advancing tunnelling: recognising a UK engineering legacy
}

Vikki Edmondson BSC, MEng, CEng, FICE, MIStructE, FCIHT, FIHE, FCMI, CMgr, PGCE, FHEA

Senior Lecturer in Civil Engineering, Department of Mechanical and Construction Engineering, Northumbria University, Newcastle upon Tyne, UK (corresponding author: vikki.edmondson@northumbria.ac.uk) (Orcid:0000-0001-9982-0751)
Fred Sherratt PhD, MCIOB, CBuildE, MCABE, FHEA

Senior Lecturer in Construction Management, Department of Engineering and the Built Environment, Chelmsford, UK (Orcid:0000-0002-3255-7562)

Richard Roff CEng, FIMechE

Group Process Safety Manager, Costain, Maidenhead, UK

Andy Levett MSC

SHE Manager, Costain, Maidenhead, UK

Between 1760 and 1820, the Georgians pioneered modern tunnelling, constructing 47 tunnels for canals across the UK. In 1789, the then longest canal tunnel in the UK was completed after 5 years and 4 months of construction; at $3490 \mathrm{~m}$, the Sapperton tunnel conveyed the Thames and Severn Canal. But there were many failures, often involving loss of life; from these, as much as from the successes, tunnelling techniques and skills were developed. The mastery of tunnelling techniques for safely traversing through the earth remains challenging for civil engineers. Since 1965, there have been over 100 reported tunnel failures across the world. While Georgian historic structures are familiar on the skylines of today's cities, a further hidden legacy can also be discovered from the past of collective engineering experiences. This paper reviews the causes of tunnelling success and failures, bequeathed to civil engineers by their Georgian predecessors, and seeks to derive lessons for today's civil engineers.

\section{Tunnelling in Georgian Britain}

In the period 1760-1820, at the height of the Industrial Revolution, Georgian civil engineers constructed a great number of the canals in Britain. At a time when the demand for engineering expertise was fierce, five chief engineers, James Brindley (1716-1772), Robert Whitworth (1734-1799), William Jessop (1745-1814), Josiah Clowes (1735-1795) and John Snape (1737-1816), were principally engaged with major projects, involving tunnels typically exceeding $500 \mathrm{~m}$ for the new waterways.

These chief engineers were recognised as having 'an extensive acquaintance with the disposition, inclination and thickness of the various strata of matter, which compass the soil or land of the British Islands' so as 'to avoid many errors incident to those who are destitute of this knowledge' (Rees, 1819). They acted as consultants to canal company management committees, preparing plans and specifications that would then be implemented by a resident engineer, who might once have been their assistant. The success of a project largely rested with the resident engineer, who remained and supervised a tunnel's construction to completion, a task that might take 5-10 years (Burton, 2015). During this time, chief engineers might be called on to act as troubleshooters to resolve construction problems requiring specialist advice.

Undoubtedly, Georgian engineers were ingenious; for evidence, one need only take recourse to their method for setting out the alignment and level of a canal tunnel underground. Most tunnels started with the sinking of shafts, with the heading then progressed from the shaft bottom. Simms (1844) recommended that if a tunnel was to be completed within 1 year, the maximum desirable distance between shafts was 100 yards (yd) $(91.4 \mathrm{~m})$. By 1840 , a triangular frame with wooden positioning prisms had been adapted to align 28 pound $(12.7 \mathrm{~kg})$ weighted copper plumb bob wires into the base of a shaft, from which the course of the tunnel heading was fixed, as shown in Figure 1. Indeed, chief engineers' careers often flourished as a consequence of the prowess at setting out (Roberts, 1977).

The Georgian tunnelling technique was relatively straightforward; once the heading of the tunnel had been excavated, the bore was gradually enlarged to the final cross-section specified by the chief engineer. To achieve this, it was often necessary to install temporary works in the form of timbers to support the roof, prior to a permanent lining of the brick or stone being installed. The final cross-sectional profile of the tunnel needed to be designed to accommodate the load-bearing characteristic of the ground through which the tunnel passed. Yet Georgian engineers had limited understanding of soil/structure interaction, and therefore, tunnel profiles were selected largely on past experience of failure. As a consequence, elliptical or parabolic profiles became often favoured, as these were able to resist earth pressure in most directions.

While the Georgians had many successes, they also encountered problems. Contemporaneous with the development of canal infrastructure came the establishment of independent contractors and subcontractors or 'hag-masters'. The first Georgian canal tunnels were largely built under a gang piecework system, with each gang leader making a separate agreement with the canal company management committee, a system likely developed from the working practices of coal miners, where it had 'long been the practice for groups to combine under a working leader to extract and raise coal' (Household, 2009). The local knowledge and experience of colliers were valued by the Georgians. Early in the canal age, the miner was really the only person skilled enough to complete tunnelling 


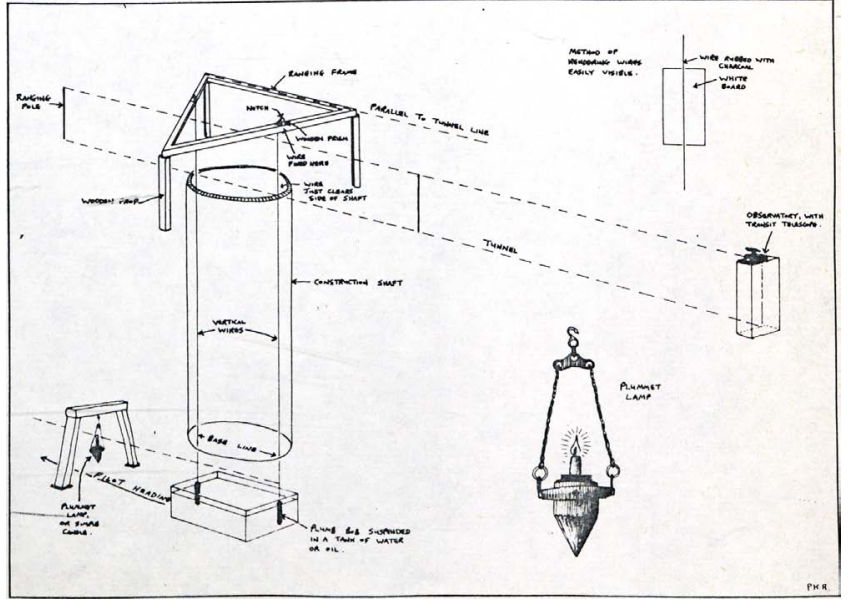

Figure 1. Method of achieving correct tunnel alignment underground (Roberts, 1977)

excavation work, and 'there are numerous recorded instances of men being recruited by the canal companies' (Roberts, 1977).

As the Georgian era progressed, it became practice to ask for a bond, pledging the completion of tunnelling work within a certain time period. Ultimately, this led to the unification of gangs under one leader, in what became contractors, yet 'a contract being one made, it seemed to be regarded as natural that the contractor should set his wits to work the most of it. This was to be done on the one hand by grinding his labourers under the pressure of the truck system and the "tommy" shop and on the other hand by "scamping” his work' (Broadbridge, 1974).

Roberts (1977), in his comprehensive study of British canal tunnels, confirms that to protect profits, it was normal for early contractors to produce inferior work at elevated prices. Skimping on materials for timbers, ropes, baskets and other equipment, combined with a general inability to organise and supervise the scale of the civil engineering project being undertaken, was arguably a primary reason for accidents and loss of life at the start of the Georgian era.

In January 1784, work started on the Sapperton tunnel, which is situated on the Thames and Severn Canal and was a key artery route for the conveyance of Staffordshire coal to London. The $3490 \mathrm{~m}$ tunnel was between 1789 and 1811, the longest in Britain. Today, it has still been surpassed in length only by two canal tunnels (Standedge and Strood) and ten railway tunnels (Sivewright, 1978). The initial contractor on the project, Charles Jones, was typical of the early Georgian era and was later replaced. Jones was often drunk, failed to pay his team regularly and when at work, 'there was plenty evidence of muddle, but none of organised progress' (Household, 2009). Household writing about events at the time reports that many lives were lost at Sapperton, some clearly through negligence. A report in the Gloucester Journal stated that 'one man was killed a few days ago by the carelessness of his companion, who suffered one of the boxes used in drawing the earth up the shaft, to fall down into the pit, which killed the person at the bottom' (Anon, 1787).

As shown in Figure 2, sections of the Sapperton tunnel passed through fuller's earth, and the chief engineer Josiah Clowes, on encountering these conditions, recognised that a brick lining would be required (Household, 2009).

To assist with the installation of the required lining, Clowes devised a 'model or driving frame', a wooden mould, perhaps the earliest example of specialist tunnel driving equipment (Roberts, 1977). Yet Charles Jones frustrated the use of the proposed driving frame, failing to enlarge the tunnel bore sufficiently to

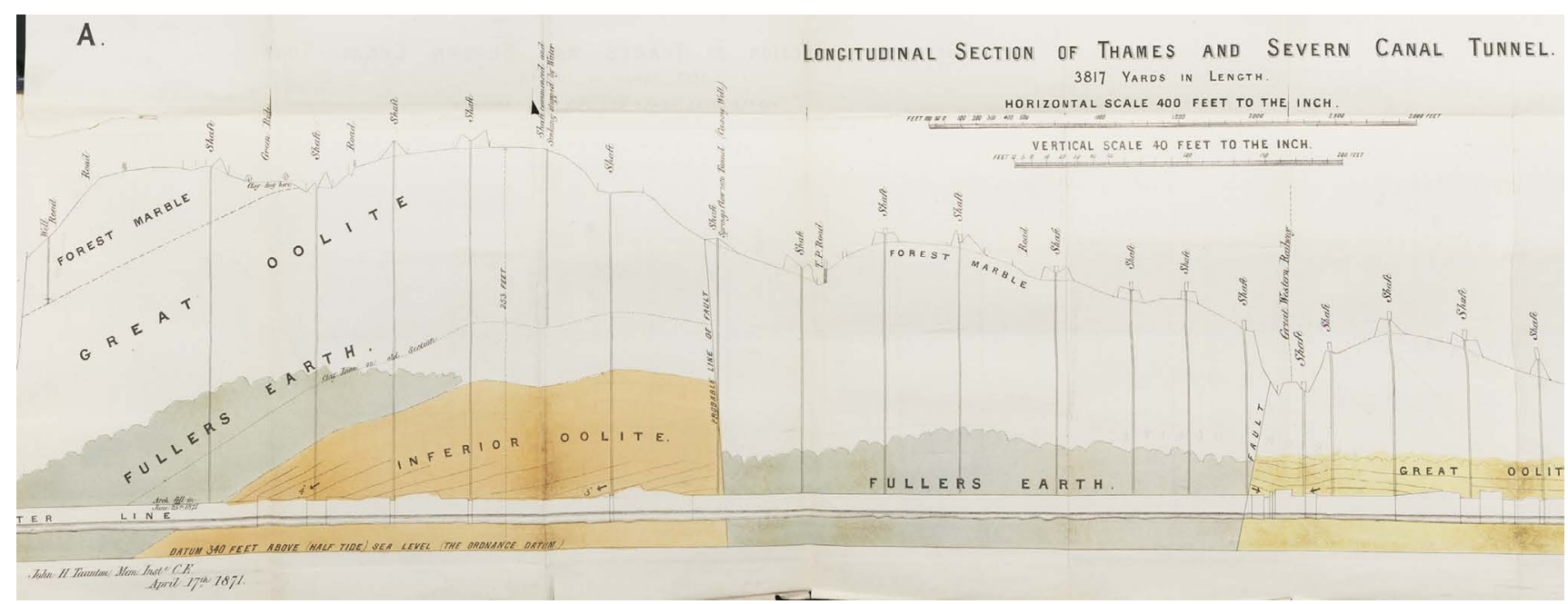

Figure 2. Longitudinal section of the Sapperton tunnel (image courtesy of the Institution of Civil Engineers (ICE)) 
enable its use. This led to a collapse of a section of the tunnel roof, causing a depression or sinkhole to develop at the surface.

Further, it became apparent following completion that 'scamping' had indeed occurred, with some sections of the tunnel having been built with a single skin of brickwork instead of the three required (refer to Figure 3).

A cavity had also been left behind the brickwork lining, so with the passage of time, 'lumps of fuller's earth fell from the roof of the crown, rolled to the sides and distorted the springing of the arch' (Household, 2009). Over time, it also became clear that Clowes had little cognisance of the interaction between the tunnels' clay lining and the surrounding earth. The purpose of the clay lining was to make the canal watertight when filled; however, on occasions when the canal was short of water or drained for examination, it was possible for this lining to dry out and crack. Household (2009) reported that water was then able to pass through the cracks in the lining, causing the surrounding fuller's earth to swell and exert pressure on the masonry lining, typically at the tunnel invert. In 1879, 90 years after the Sapperton tunnel opened in April 1789, this led to $270 \mathrm{yd}$ ( $247 \mathrm{~m}$ ) of the tunnel's invert being replaced; however, this still demonstrates a reasonable design life by modern standards.

Many of the problems of construction (and subsequent maintenance) arose directly from 'a lack of knowledge of the sequence and physical characteristics of the rock strata to be penetrated' (Roberts, 1977). During the Georgian era, geological and hydrological knowledge was generally not well advanced. The Georgians also had limited knowledge of slope stability and therefore before 1800 avoided excavating cuttings deeper than $9 \mathrm{~m}$, favouring instead the installation of shallow cut-and-cover tunnels.

Georgian chief engineers endeavoured wherever possible to select and plan the initial route for a tunnel through favourable topographical and geological conditions. Yet as geotechnical site investigation was in its earliest infancy, this hampered their attempts, with decisions being largely based 'on cases where the surface geological materials were known to be unsuitable for canal construction' (Farrington, 1972). Understanding of the below-ground conditions was for the most part developed during the 'actual tunnelling process itself, where flexibility and adaption of technique and materials' (Roberts, 1977) were essential to success. Any pre-tunnelling study of the ground was limited to shallow boreholes or exploration shafts typically no greater than $1800 \mathrm{~mm}$ dia., these being the techniques employed by mining engineers. William 'Strata' Smith, one such mining engineer, worked on the Somerset Coal Canal in 1805 and was, through his experience, able to avoid a route where geological features would mean that there was a risk of loss water from the canal. William Smith was later credited with producing the first geological map of part of Great Britain in 1815, shown in Figure 4.

Tunnel roof falls were a relatively common occurrence, as Georgian engineers encountered 'unforeseen ground conditions'. At Bilsworth in July 1804, during the construction of a $2812 \mathrm{~m}$ tunnel to convey the Grand Union Canal, a 20 yd (18.3 m) section of tunnel collapsed,

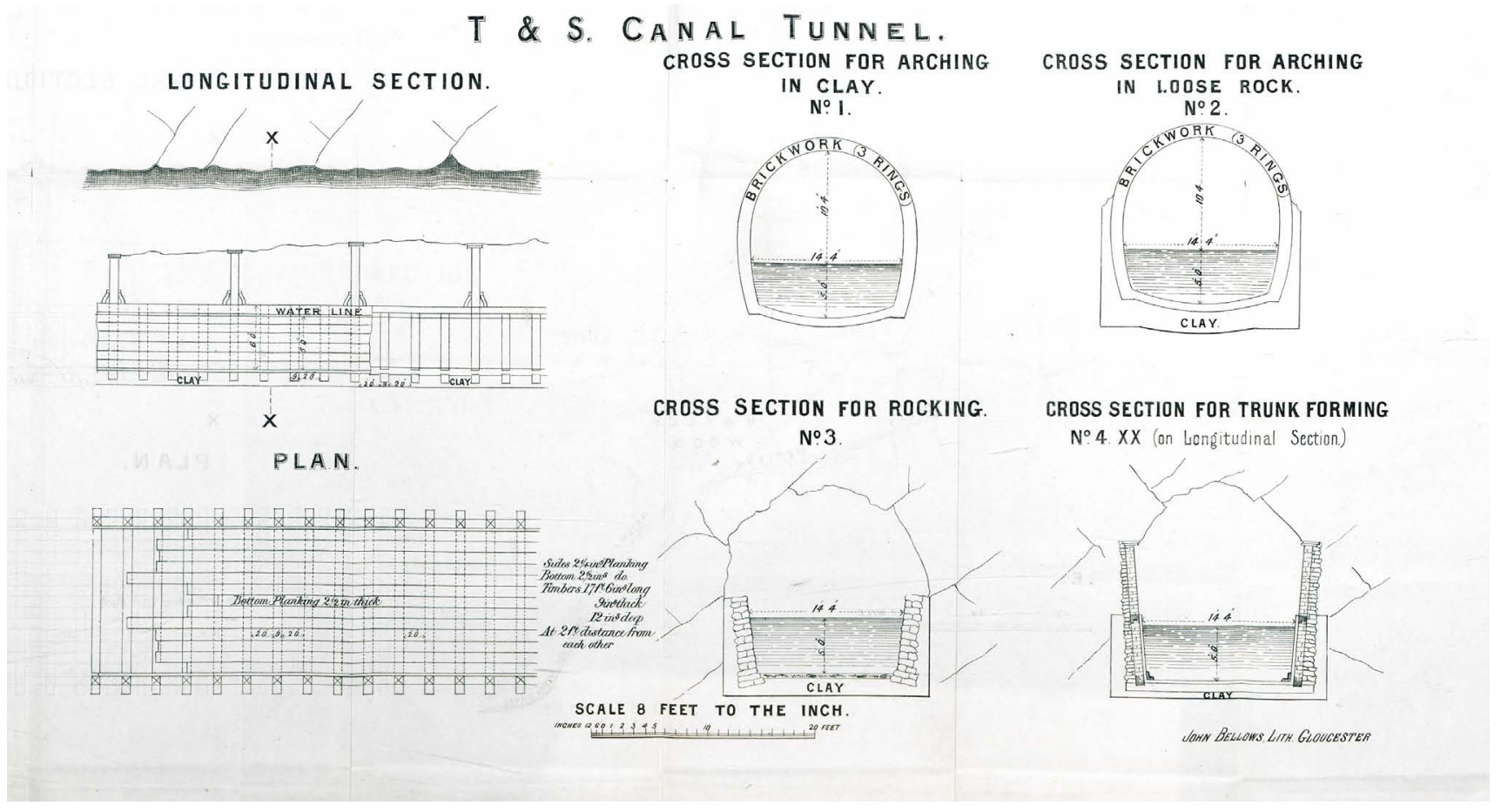

Figure 3. Cross-section of the Sapperton tunnel (image courtesy of the ICE) 


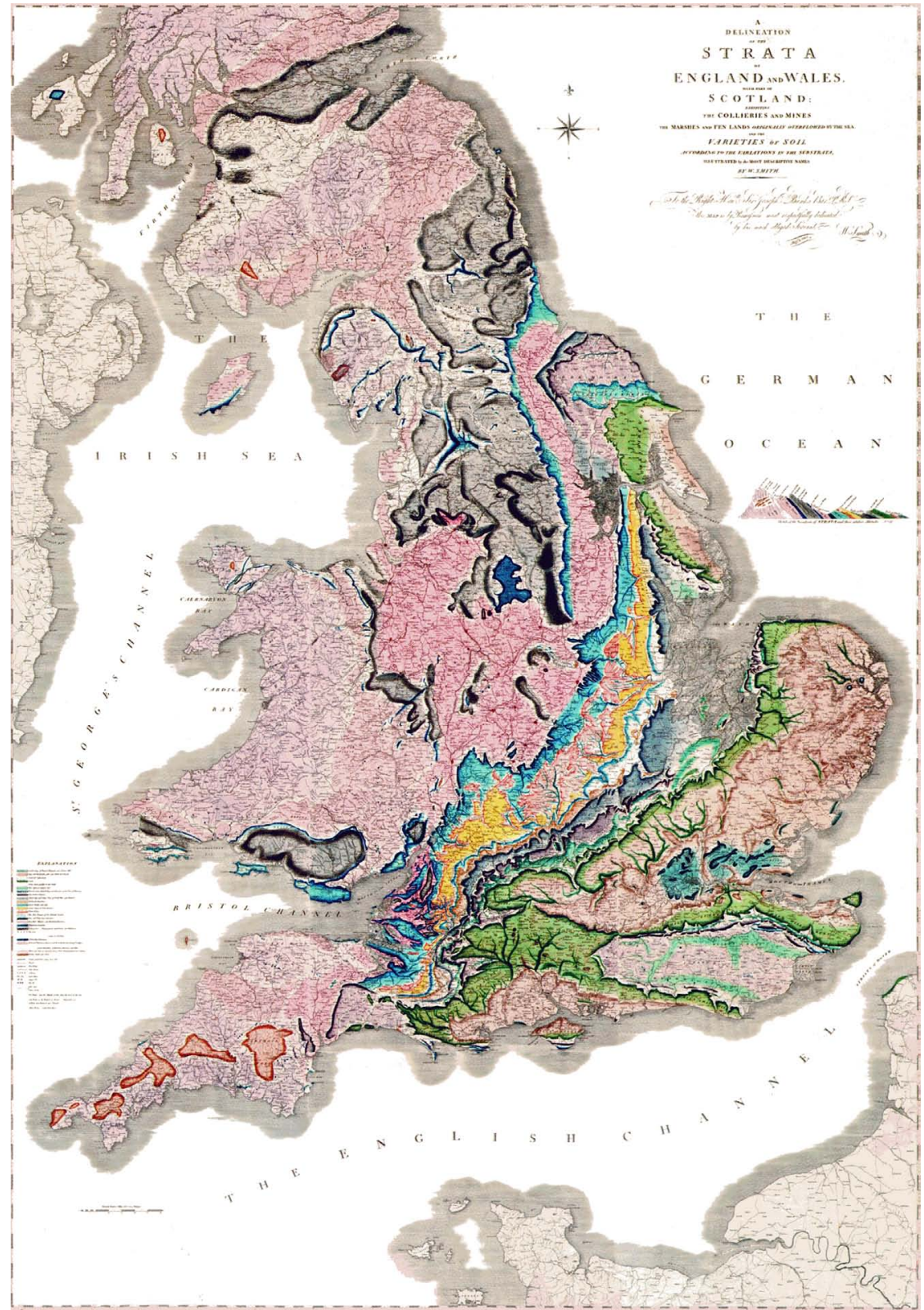

Figure 4. William Smith's 1815 geological illustration of part of Great Britain (image courtesy of the ICE)

killing one man and setting work back some months (Faulkner, 1972). The work at Bilsworth was started in 1793, with Barnes as the resident engineer. Groundwater ingress proved almost immediately to be a significant problem, drowning out the tunnelling operations, so that works almost stopped in 1796. William Jessop, the chief engineer, consulted with his peers John Rennie and Robert Whitworth, who proposed that the tunnel be constructed on a slightly different line. Barnes then proceeded with the work, constructing from May 1796 to the middle of 1802 a pilot tunnel, beneath that of the main, to act as a drain for unwanted water. Notably, William Jessop did not complete his plans for the cross-section of the tunnel until March 1802, by which time Barnes had worked on the heading of the drainage tunnel for just under 6 years. 'The sides wall and the crown were to be 17 in, or two bricks, thick and the inverted arch 13in or $1 \frac{1}{2}$ bricks, thick' (Faulkner, 1972).

The Georgians' knowledge of hydrological conditions was poor; Harecastle (old) canal tunnel (1775), Oxenhall canal tunnel (1794), Bosworth canal tunnel (1813) and Harecastle (new) canal tunnel (1827) were among those that experienced problems with groundwater. As well as constructing 'pilot' tunnel headings to draw water away from the main tunnel line, Georgians also developed pumps. 'When Brindley began to work on the tunnel at Harecastle on the Trent and Mersey [canal], he had to build a crude atmospheric 
engine to his own design' (Burton, 2015). Similarly, before Thomas Telford started work on the Harecastle (new) in 1825, a $2676 \mathrm{~m}$ bypass to the older tunnel built in 1775, he ordered Boulton and Watt steam engines for each portal to pump water as shown in Figure 5.

The Harecastle (new) canal tunnel, situated on the Trent and Mersey Canal, was one of the last tunnels built in the Georgian era, completed in April 1827. The contractor on the project was one of the greatest to emerge from the gang system, being Pritchard and Hoof of King's Norton, who were able to construct the canal tunnel without the loss of a single life. The tunnel was also constructed in a record time for the era of $550 \mathrm{~d}$, a further testimony to the developing organisational skills of the new larger Georgian contractors. A summary of the key themes of learning raised by studying Georgian tunnelling engineer is included as Table 1.

\section{Tunnelling failures since $\mathbf{1 9 6 5}$}

The Georgian era can be characterised as a time when tunnelling technology, as well as knowledge of geological and engineering

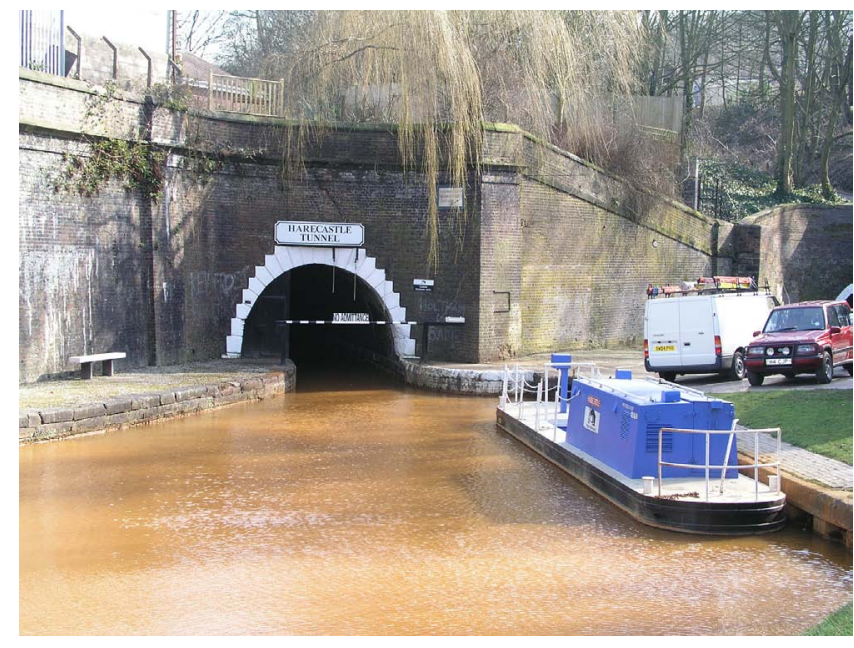

Figure 5. The completed south portal of Harecastle (new) canal tunnel (image courtesy of the ICE) principles, was emerging. The development of Georgian tunnelling expertise was driven by the prolific building of canals, to transport commodities such as coal and cotton during the Industrial Revolution. Like in the Georgian era, today, society is again experiencing a resurgence of tunnelling activity, particularly in developing countries (refer to Figure 6).

Travelling forward two centuries, it might have been anticipated that tunnel collapses, as a consequence of unforeseen ground conditions, water ingress or poor construction management, would have become a rarer event. Yet since 1965, there have been over 100 reported tunnel failures across the world. Table 2 lists some of the notable failures that have occurred within the last two decades, while Figure 7 categorises tunnel failures since 1970 between those employing the 'New Austrian Tunnelling Method' (Natm) and other methods.

On 21 October 1994, three parallel tunnels being constructed as part of the Heathrow Express Rail Link at London Heathrow airport collapsed. The sprayed-concrete-lined tunnels were constructed using the Natm and, while not a new technique, it had not been thoroughly tested in the London Clay together with the use of compensation grouting. This non-fatal catastrophic event is still considered to be one of the worst civil engineering disasters in the UK during the past 50 years.

The Health and Safety Executive (HSE) in the UK undertook extensive investigations not only into the incident but also into the Natm construction methodology, at the request of the Health and Safety Commission. Following a criminal trial in February 1999, the heaviest fines ever imposed, $£ 1 \cdot 2$ million plus costs, were levied against the principal contractor Balfour Beatty, with a further $£ 500000$ against the Natm advisors Geoconsult. Both firms were found guilty of falling 'seriously short' of the appropriate standards, with the HSE commenting that they were 'seriously concerned that those introducing this technique, and their Natm advisers, into potentially high risk locations seem not to have adequately taken account of past experience' (HSE, 1996), including the Munich Metro tunnel collapse that had occurred 1 month earlier.

Table 1. Summary of the key themes of learning raised by studying Georgian tunnelling engineers

- Georgians were often at the forefront of applying new technologies - for instance, Strood tunnel on the Thames and Medway Canal utilised probably for the first time an astronomers' transit telescope. The telescope was primarily selected for setting out because the $3608 \mathrm{~m}$ length of the tunnel inhibited conventional setting out by ranging. The Georgians, driven to solve practical problems in order to construct Britain's canal network, were able to develop and enhance many engineering techniques with success.

- The approach to the delivery of Georgian civil engineering consultancy, embracing as it did the chief engineer and the resident engineer, placed great value on engineering expertise and experience. Georgians often progressed their understanding of tunnelling techniques by learning directly from previous failures.

- Assessment of geological conditions was not well understood, and this led to groundwater inundation and to tunnel roof falls, resulting in some incidents involving the propagation of surface depressions.

- With the emergence of independent contractors, Georgian intent on profit failed to organise and enforce site health and safety procedures to protect the well-being of tunnel workers, and lives were lost on most projects. However, towards the end of the era, there were real improvements in both the safety and the management of tunnel construction.

- Chief engineers completing tunnelling in the Georgian era were experts at setting out the horizontal alignment both above and below ground. The selection of an appropriate route, in terms of topography and geology, and then the accurate setting out of a tunnel were primary concerns of the Georgian engineer. 


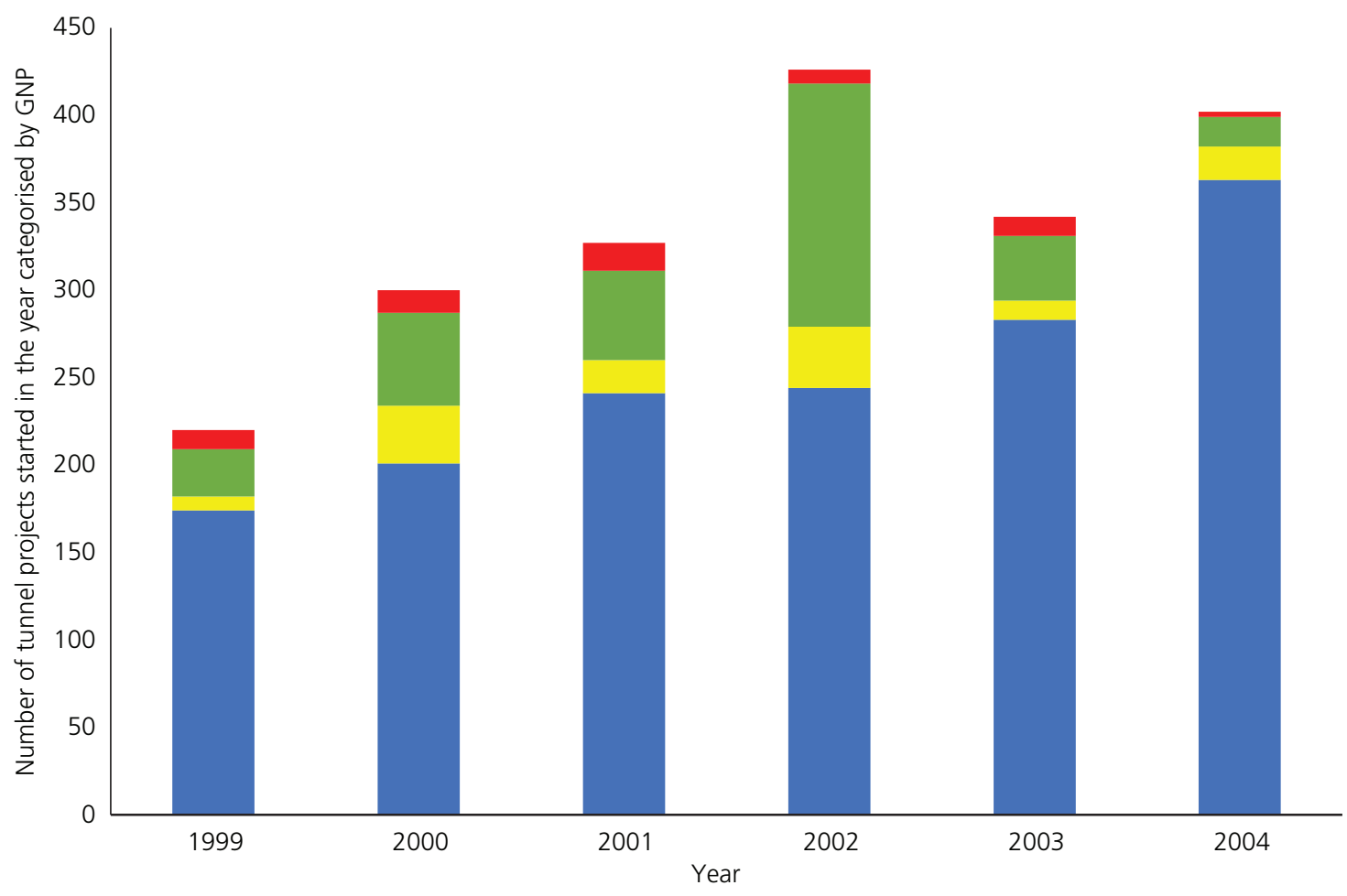

- GNP > US\$9386-US\$9386 > GNP > US\$3036 -US\$3036 > GNP > US\$766 - GNP < US\$766

Figure 6. Estimated tunnelling activity between 1999 and 2004 by gross national product (GNP) (HSE, 2006)

The HSE (1996) published their findings on the Natm methodology shortly after the criminal trial had been completed. The report highlights a comprehensive but simple set of lessons to be adopted by the industry on future Natm contracts. Yet in the immediate years following its publication, further tunnel failures occurred using Natm across the world, as shown in Figure 7. For instance, in 2007, seven people lost their lives in São Paulo, Brazil, when a section of Natm tunnel for a new metro station collapsed, creating a $30 \mathrm{~m}$ deep hole. The Companhia do Metropolitano de São Paulo investigation into the failure reported that the collapse occurred as a result of unforeseen ground conditions, exacerbated by a high water table following heavy rain. Completing a study on the failure, the São Paulo Instituto de Pesquisas Tecnológicas stated that the geology of the area had been studied for 10 years prior to the

Table 2. Notable tunnel collapses occurring during tunnel construction since 1994 (CEDD, 2015)

\footnotetext{
- Munich Underground, Germany, 27 September 1994

- Heathrow Express, UK, 21 October 1994

- Los Angeles Metro, USA, 22 June 1995

- Motorway tunnels, Austria, 1993-1995

- Docklands Light Rail, UK, 23 February 1998

- Athens Metro, Greece, 1991-1998

- Lærdal Road tunnel on European highway E16, Norway, 15 June 1999

- Shanghai Metro, China, 2003

- Sewage tunnel, Hull, UK, 1999

- Taegu Metro, South Korea, 1 January 2000

- Channel tunnel rail link, UK, February 2003

- Météor Metro tunnel, France, 14 February 2003

- Shanghai Metro, China, 2003

- Guangzhou Metro line 3, China, 1 April 2004

- Singapore's mass rapid transit (MRT), 20 April 2004

- Kaoshiung Rapid Transit, Taiwan, 29 May 2004

- Oslo Metro tunnel, Norway, 17 June 2004

- Kaoshiung Rapid Transit, Taiwan, 10 August 2004

- Hsuehshan tunnel, Taiwan, 1991-2004
}

- Barcelona Metro, Spain, 27 January 2005

- Lausanne M2 Metro, Switzerland, 22 February 2005

- Lane Cove tunnel, Australia, 2 November 2005

- Kaoshiung Rapid Transit, Taiwan, 4 December 2005

- Stormwater Management and Road Tunnel, Malaysia, 2003-2006

- São Paulo Metro station, Brazil, 15 January 2007

- Guangzhou Metro line 5, China, 17 January 2008

- Langstaff Road trunk sewer, Canada, 2 May 2008

- Circle line 4 tunnel, Singapore, 23 May 2008

- Hangzhou Metro tunnel, China, 15 November 2008

- Cologne North-South Metro tram line, Germany, 3 March 2009

- Brightwater tunnel, USA, 8 March 2009

- Seattle's Beacon Hill Light Rail, USA, July 2009

- Cairo Metro tunnel, Egypt, 3 September 2009

- Shenzhen Express Rail Link, 27 March 2011, 4 and 10 May 2011

- Hengqin tunnel, Macau, 19 July 2012 


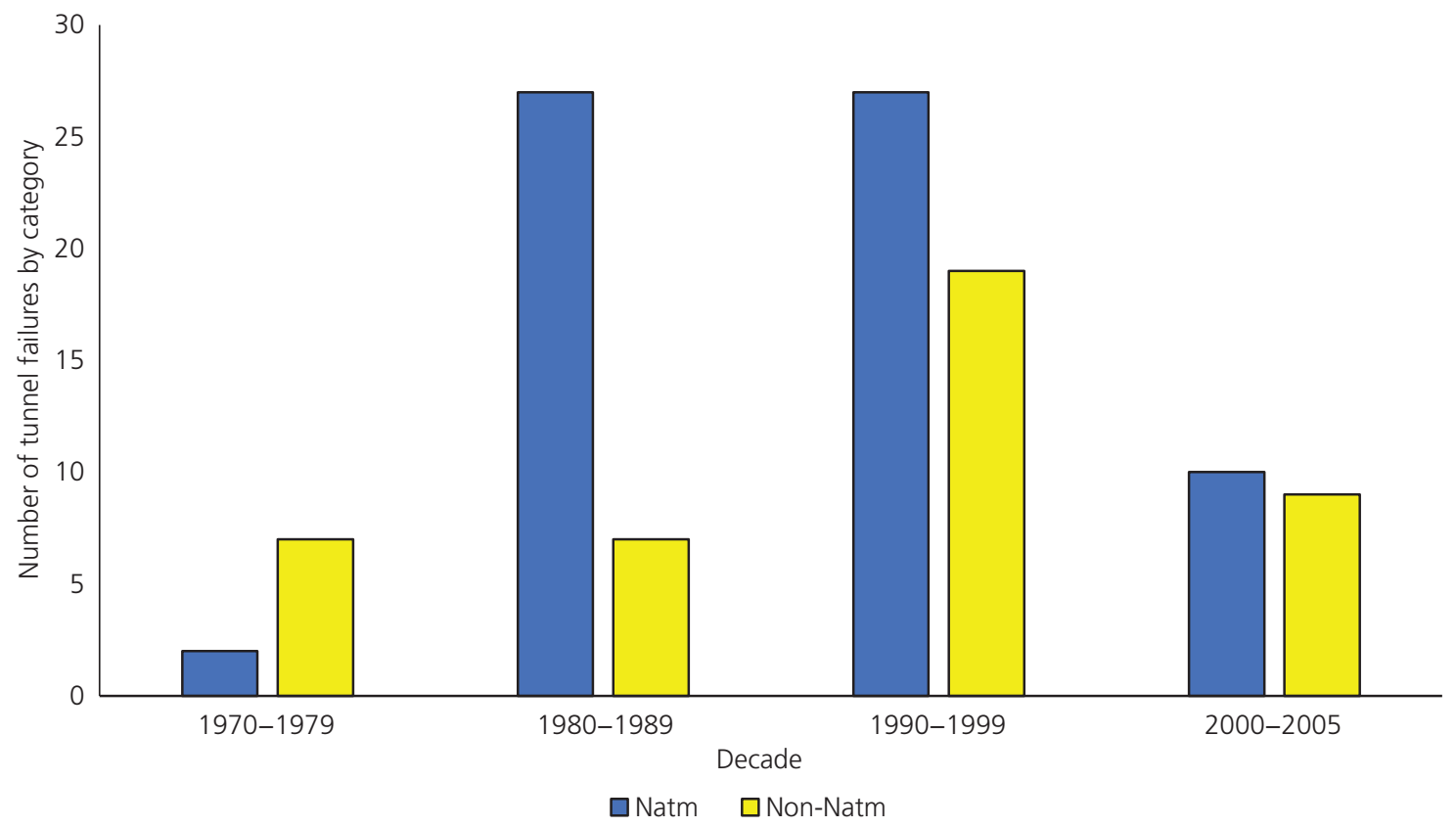

Figure 7. Number of tunnelling failures per decade (HSE, 2006)

project and that collapse had occurred as a consequence of a failure of design, construction and risk management. The designer had insufficient influence over the larger tunnelling contractor, 'unvalidated' design changes occurred during construction and 'there was no evidence of any back analysis of data from monitoring' (Hansford and Wynne, 2009).

Whatever the accepted cause of the São Paulo collapse, the themes of failure are evidently similar to those experienced by the Georgians some 200 years earlier. Parallels of failure are also evident in recent tunnel collapses adopting other construction methods. The Lærdal runnel experienced a rock cave-in in 1999 while being constructed by using the drill-and-blast method. A $17 \mathrm{~m}$ length of the tunnel crown collapsed, and the failure was considered to have occurred due to the lack of understanding of the geological conditions and their influence on stability, along with poor communication between the driller and the engineer (CEDD, 2015). The ground conditions were such that it was possible for a clay layer to exert a squeezing force on the rock mass of the tunnel, causing it to weaken. The Hull sewage tunnel was constructed using a tunnel-boring machine, and here, a reinforced concrete segmental lining subsided, resulting in a surface depression. The potential cause of failure was attributed to fluctuation of groundwater levels caused by tidal effects, resulting in the movement of the tunnel lining. In 2004, a section of an open-cut tunnel being constructed for a new metro line in Singapore collapsed, killing four workers (CEDD, 2015). A number of causes were suggested, including underdesign of the temporary works strut-waling beam connection, lack of effective monitoring and lack of regard for on-site warnings including excessive wall deflection.

\section{Key lessons from the Georgian engineering legacy}

A 'broad-brush' review of the possible causes suggested for recent tunnelling failures (CEDD, 2015) leads to two distinct conclusions: failures occur due to either consequences of geology or consequences of management. Given the acknowledged potential for complexity within such categorisations of 'causality' (e.g. Reason (1990)), an approach was made here that instead focused on the dominant discourses (Burr, 2003) that surround these two 'causes' of engineering failure within these different eras. Discourses reflect the ways in which society understands the world and can be found in the ways that the members of society communicate with each other through talking, through texts, visually or through other methods. In examining the archival data for this paper, specifically how engineers report, reflect and consider engineering failure in both the Georgian times and the present day, the authors are better able to reveal what is prioritised, what is dismissed and how such positioning and emphasis contributes to wider understandings of failure in practice. Through this analysis of the dominant discourses of engineering failure, shared understandings within these specific contexts are revealed; thus, the authors are better able to explore the engineering legacy of the Georgians and its influences on contemporary practice.

By far the most frequent cause assigned to tunnelling failure in recent years can perhaps be more accurately identified as failures of geotechnical knowledge, involving the lack of understanding of the site-specific geology, resulting in poor technological and management decisions. The consequences of unforeseen ground conditions revealed during the tunnelling process, such as the 
location of an unidentified lens of sand within the ground that led to the collapse of the Gibei railway tunnel in Romania (1985), or identification of the presence and orientation of faults and fissures in rock, such as those that resulted in a cave-in during the construction of the Holmstrand Road tunnel in Norway (1981), are often termed 'unexpected', 'unfavourable' or 'difficult'. Often the 'lesson to be learnt' from such contemporary failures is to increase or improve geotechnical knowledge through more robust ground investigation.

When this contemporary perspective is considered alongside that of the Georgians, one aspect that quickly emerges is that the Georgians knew that they did not know everything, and so they were better able to acknowledge this within their engineering practice. Twenty of the 34 significant canal tunnels (tunnels with a length of more than $500 \mathrm{~m}$ ) constructed by Georgians in the UK were completed prior to 1801 , before the issue of the first Ordnance Survey map in the UK (Ordnance Survey, 2017). At that time, the assessment and evaluation of geological conditions were not well understood, yet the Georgians' attitude towards geotechnical knowledge can perhaps provide civil engineers with the most important lesson to be learnt.

Contemporary civil engineering, with its 'advanced' techniques and approaches to geotechnical investigation, has arguably developed a discourse of geotechnical knowledge as substantiated by 'fact'. Should knowledge be lacking, then more knowledge must be the solution. However, when considered from a pragmatic perspective, the ability to know all the facts about the ground before starting tunnelling becomes non-sensical. Indeed, the discourse of 'geotechnical fact' can only serve to reinforce and perpetuate the false confidence that contemporary techniques have themselves developed and which has arguably led to the continuation of such ascribed failures in practice. Further evidence of the potential problems associated with this discourse is illustrated by tunnelling failures ascribed to groundwater. Again, the Georgians were aware that their knowledge of the behaviour of groundwater was lacking and this did lead to tunnelling failures, yet groundwater also remains a problem in contemporary tunnel construction. Often noted as unexpected, fluctuations in groundwater caused by either heavy rainfall or tidal influences, both of which are in fact highly predictable, remain a contributory cause of failures, such as that of the Hull sewage tunnel in the UK (1999). That groundwater is itself a thing in flux should perhaps hold more influence, yet it seems unable to mount an effective challenge to this dominant discourse of inflexible fact, despite its significant contribution to geotechnical conditions through either increases or decreases in pressure, during construction or over time, and impact on various strata such as swelling clay, running sand or weathered rock.

In contrast to contemporary discourse, the Georgians relied on an alternative and instead placed much more value in a discourse of engineering expertise and experience. Nor was this expertise limited to the engineers themselves; the Georgians were keen to seek out the experience and knowledge of others - for example, local colliers whose knowledge of local geotechnical conditions was well respected. One resident engineer, John Pinkerton, when challenged about the slow progress of the Dudley tunnel (1791), commented that they had encountered 'circumstances not apprehended from the information which had been collected by the most intelligent colliers in the neighbourhood' (Grittings, 1974). Such an approach is something of a contrast to the silos of professionalism and professional knowledge found in contemporary engineering practice.

Arguably more inclusive and aware of its own limitations, this discourse of expertise and experience is much better placed to recognise, suggest or even fully expect the unexpected, and the combination of assigning both a chief engineer and a resident engineer to a project enabled that experience to be readily drawn on (Roberts, 1977) in both the selection of an appropriate route for the proposed tunnel and the determination of suitable methods for its construction. However, it must be noted here that the Georgian reliance on expertise and experience was not perhaps as comfortable to them as it might seem. Indeed, it was during the Georgian period that William Smith, who worked on the Somerset Coal Canal (1805), created the first geological map of Great Britain in 1815, thus initiating the process of recording and disseminating knowledge about the ground and so arguably establishing the discourse of geotechnical fact that subsequently grew and developed and which now dominates today.

Despite their more philosophical approaches to geotechnical knowledge, the Georgians were not immune to the more mundane practices of the construction industry as a whole, and it was during this time that construction contracting as society still recognises it today first emerged and the familiar pressures of time and money started to take hold. Although the resident engineer was a constant presence on Georgian tunnelling projects, it was the gang masters and then finally, towards the end of the era, the emerging contractors who maintained supervision of the operations, and they were therefore charged with safety and were often found lacking. As this was also a time in which human life was less valued, and construction site management skills focused more on profit than health and safety, workers' lives were lost on most tunnelling projects of the era. Yet towards the end of the era, large contractors began to emerge, the greatest being Pritchard and Hoof of King's Norton, who were able to construct the second Harecastle canal tunnel (1827) without the loss of a single life.

The segregation between engineering and construction practice that started with the Georgians remains in place today, a discourse of 'construction as management practice' perhaps most readily associated with contemporary construction projects, retaining its dominance over that of engineering and engineering expertise. This is a discourse that prioritises the management values of time and money within the construction process above all else, which still has significant consequences for engineering practice as evidenced 
by the (albeit smaller) number of contemporary failures that can be ascribed to the consequences of management. The failures of planning and management are readily demonstrated in the collapse of the Heathrow Express tunnel in the UK (1994), where ambitions on reductions in cost and time led to remedial works three times that of the original contract sum. Human life is also still vulnerable to such management pressures, as the collapse of the diaphragm walls during the construction of the Singapore MRT in 2004 and subsequent loss of four workers' lives sadly demonstrate. Indeed, it can be suggested that management constraints around time and cost may also limit robust site investigation and testing prior to construction, thereby also contributing to the geotechnical knowledge failures previously noted.

Yet the consultancy process by which the Georgian engineers sought to remain physically present on their projects arguably presented something of a practical challenge to this emergent discourse and a valuable lesson to be learnt around the discovery of unexpected events before they evolve into significant loss and how this is communicated. Analysis of contemporary tunnelling failures also notes communication during the construction process to be vital between the tunnelling workers and the engineering decision makers, as the drilling team notes cracks, noises or water ingress, and remedial action is prioritised accordingly. While the pressure to construct quickly and cheaply must be acknowledged, when production accelerates past predicted parameters, and support systems and safe working practices for tunnel stability can no longer keep up, open discussions of emerging data and the freedom to stop and reassess may be the last line of defence against failure. For example, had the abnormal drilling rates experienced on the Lærdal tunnel in Norway (1999) been recognised as unexpected and then communicated to a resident engineer, the subsequent cavein could have perhaps been avoided.

\section{Conclusion}

Although construction management in its current contracting-based form has been present alongside civil engineering from Georgian times, the way that the Georgians sought to overcome the problems this brings can perhaps inform contemporary practice. Overall, it could be suggested that civil engineers responsible for the planning and design being there and being more engaged during the construction phase of any tunnelling works, being able to sense changes and having effective immediate processes to intervene would enhance the contemporary civil engineering profession. Such an approach would consequently enable engineers to both develop and draw on their expertise, rather than only rely on limited geotechnical fact, facilitating safer working as tunnelling operations progress and thereby better acknowledging and ensuring the learning legacy of the Georgians in contemporary civil engineering practice.

\section{Acknowledgements}

The authors would like to acknowledge the support of Bill Hewlett, technical director of Costain; Mike Chrimes, retired librarian of the ICE; and Robert Heffernan, librarian at the ICE.

\section{REFERENCES}

Anon (1787) Gloucester Journal, 22 January.

Broadbridge SR (1974) The Birmingham Canal Navigations: Volume 1 1768-1846. David \& Charles, Newton Abbot, UK.

Burr V (2003) Social Constructionism, 2nd edn. Routledge Hove, UK. Burton A (2015) The Canal Builders - the Men Who Constructed Britain's Canals, 5th edn. Pen and Sword Transport Barnsley, UK.

CEDD (Civil Engineering and Development Department) (2015) Catalogue of Notable Tunnel Failures - Case Histories (up to April 2015). Mainland East Division, Geotechnical Engineering Office, Government of the Hong Kong Special Administrative Region, Hong Kong.

Farrington JH (1972) Morphological studies of English canals. University of Hull Occasional Paper in Geography 20: 22-24.

Faulkner AH (1972) The Grand Junction Canal. David \& Charles, Newton Abbot, UK.

Grittings DA (1974) Dudley Canal Tunnel - a Guide to Commemorating the Restoration of the Tunnel, 2nd edn. Dudley Canal Trust Dudley, UK.

Hansford H and Wynne A (2009) Catalogue of failures led to São Paulo collapse. New Civil Engineer, 25 June. See https://www. newcivilengineer.com/catalogue-of-failures-led-to-so-paulo-collapse/ 5204029.article (accessed 14/03/2017).

Household H (2009) The Thames and Severn Canal, 3rd edn. Amberley Stroud, UK.

HSE (Health and Safety Executive) (1996) Safety of New Austrian Tunnelling Method (NATM) Tunnels - a Review of Sprayed Concrete Lined Tunnels with Particular Reference to London Clay. Health and Safety Executive, Liverpool, UK. See http://www.hse.gov.uk/pubns/ books/natm-report.htm (accessed 14/03/2017).

HSE (2006) The Risk to Third Parties from Bored Tunnelling in Soft Ground. HSE Books, Sudbury, UK.

Ordnance Survey (2017) Our History. Ordnance Survey, Southampton, UK. See https://www.ordnancesurvey.co.uk/about/overview/history. html (accessed 14/03/2017).

Reason J (1990) Human Error. Cambridge University Press, Cambridge, UK. Rees A (1819) The Cyclopaedia or Universal Dictionary of Arts Science and Literature. Longmans, London, UK.

Roberts PK (1977) British Canal Tunnels. PhD thesis, University of Salford, Salford, UK.

Simms FW (1844) Practical Tunnelling. William Tiffin, Hythe, UK. Sivewright WJ (1978) Panel for Historical Engineering Works for Sapperton Tunnel. Institution of Civil Engineers, London, UK. See https://www.ice.org.uk/disciplines-and-resources/ice-library-anddigital-resources/historical-engineering-works/details?hewID $=2511$ (accessed 07/01/2017).

\section{How can you contribute?}

To discuss this paper, please email up to 500 words to the editor at journals@ice.org.uk. Your contribution will be forwarded to the author(s) for a reply and, if considered appropriate by the editorial board, it will be published as discussion in a future issue of the journal.

Proceedings journals rely entirely on contributions from the civil engineering profession (and allied disciplines). Information about how to submit your paper online is available at www.icevirtuallibrary.com/page/authors, where you will also find detailed author guidelines. 